\title{
An Electron Microscopic Cytochemical Study on Concanavalin A Binding Sites and Their Mobility in Normal and Cystic Fibrosis Fibroblasts In Vitro
}

\author{
MASAO YOKOYAMA, JEFFREY P. CHANG, (41) DAVID HOM, AND SANDRA L. WILSON \\ Division of Cell Biology, Department of Human Biological Chemistry and Genetics, Graduate School of \\ Biomedical Sciences, The University of Texas Medical Branch, Galveston, Texas, USA
}

\begin{abstract}
Summary
Concanavalin A (Con A) binding sites were visualized ultrastructurally in the cultured fibroblasts from cystic fibrosis patients, obligatory heterozygotes, and normal individuals by peroxidase labeling technique. Con $\mathbf{A}$ binding sites were localized as a continuous layer on the external side of the plasma membrane in fixed fibroblasts of the three genotypes. In living cells, Con $A$ induces both lateral and vertical movements of binding sites as expressed by cap formation and internalization of the plasma membrane. Fibroblasts of the three genotypes responded similarly to Con A treatment and failed to show significant detectable differences.
\end{abstract}

\section{Speculation}

The mannose-like residues in the carbohydrate moiety of the plasma membrane glycoprotein do not vary significantly among fibroblasts from cystic fibrosis (CF) patients, CF carriers, and normal individuals.

Cystic fibrosis, one of the common Caucasian genetic disorders, is characterized by a generalized dysfunction of the exocrine glands and involves mucin abnormalities. Although multidisciplinary research of this disease has been carried out in this institution and elsewhere $(4,5,8,11-14,25,27)$, the basic defect of this hereditary disease has not been clarified. There is increasing evidence that one aspect of the disease process involved altered function of the plasma membrane $(2-4,16,19$, $25,26,33)$. No report, however, has appeared in the past concerning the distribution of lectin binding sites at the cell surface or the effects of lectins on CF fibroblasts. Therefore, this study was conducted using Con $\mathrm{A}$ as a molecular probe for the mannose-like sugar residues (20) on the plasma membrane.

\section{MATERIALS AND METHODS}

\section{CELL CULTURES}

The fibroblast cell lines were established from skin biopsies of patients with clinically proven $C F$, obligatory $C F$ carriers, and normal individuals. The cells were grown as a monolayer on Teflon-treated coverslips (15) in Ham's F-10 medium supplemented with $10 \%$ fetal calf serum. The details of the culture technique have been described previously (9). Three genotypically different fibroblasts were always matched for subculture number, culture hours, and growth conditions for this study. Cells of both exponential and plateau growth phase were used.

\section{FIXED FIBROBLASTS}

Monolayer cells on coverslips were washed gently in Dulbecco's phosphate-buffered saline (PBS) and fixed in situ in cold
$2 \%$ glutaraldehyde in PBS for $30 \simeq 60 \mathrm{~min}$. The specimens were washed for 5 min three times in PBS and reacted with Con A (Miles Yeda, three times crystallized) in concentrations varying from $4-800 \mu \mathrm{g} / \mathrm{ml}$ PBS for different periods of time at room temperature. They were washed in PBS again and coupled with

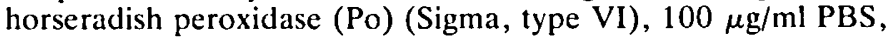
for $30 \simeq 60 \mathrm{~min}$ at room temperature (7). Some samples were treated routinely with Con $\mathrm{A}, 50 \mu \mathrm{g} / \mathrm{ml}$, for $45 \mathrm{~min}$ and $\mathrm{Po}, 100$ $\mu \mathrm{g} / \mathrm{ml}$, for $45 \mathrm{~min}$ as standard techniques. The cells were washed in PBS and fixed again in glutaraldehyde for $30 \mathrm{~min}$. They were

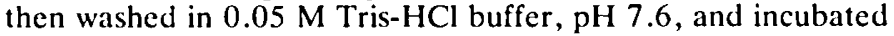
in $3^{\prime}, 3$-diaminobenzidine (DAB), $0.5 \mathrm{mg} / \mathrm{ml}$, in $0.05 \mathrm{M}$ Tris$\mathrm{HCl}$ buffer, $\mathrm{pH} 7.6$, at $37^{\circ}$ for the demonstration of Po activity in the presence of hydrogen peroxide (22). The coverslips with monolayer cells were rinsed with distilled water and postfixed in $1 \% \mathrm{OsO}_{4}$ in PBS, dehydrated in ethanol, and embedded in Spurr low viscosity embedding medium (35) in flat embedding molds. Embedded monolayer cells were separated from the coverglasses by dipping in liquid nitrogen. Desirable cells from Epon blocks were selected with the light microscope and mounted on blank Epon blocks for sectioning. Thin sections were cut with a diamond knife on an LKB ultramicrotome. Unstained sections and sections stained with lead citrate were viewed by Philips 300 and 201 electron microscopes. In addition, the human fibroblasts from scar tissue biopsy were frozensectioned at $20-40 \mu \mathrm{m}$ and exposed to Con A followed by Po coupling. Experiments were conducted to increase the permeability of the membrane to Con A by the following methods: (1) prolonged fixation by a different fixative (1\% paraformaldehyde plus $3 \%$ glutaraldehyde for $3 \mathrm{hr}$ ), (2) prolonged Con A exposure up to $16 \mathrm{hr},(3)$ freezing and thawing of the fixed cell with prolonged Con A exposure, (4) trypsinization of the cells with freezing and thawing, and (5) $10 \%$ dimethylsulfoxide washing for $48 \mathrm{hr}$ before Con A treatment. Some of the procedures are listed in Table 1.

\section{LIVING FIBROBLASTS}

Monolayer fibroblasts on coverglasses were washed gently in PBS to remove culture media. They were immersed in PBS for treatment with various concentrations of Con $A(50-100 \mu \mathrm{g})$ for different periods of time at $4^{\circ}$, washed for 5 min three times with cold PBS, then coupled with Po-PBS, $100 \mathrm{mg} / \mathrm{ml}$, for $30 \mathrm{~min}$ at $4^{\circ}$. This was the standard Con A-Po technique. After the Con APo treatment, the living cells were washed in PBS $\left(4^{\circ}\right)$, then incubated in PBS at $37^{\circ}$ for varying periods of time up to $3 \mathrm{hr}$. The warm incubation was terminated by fixation with $2 \%$ glutaraldehyde in PBS for $30 \mathrm{~min}$. They were then washed again, reacted with $D A B$, postfixed with osmium, and finally processed for electron microscopy. 


\section{CONTROL EXPERIMENTS}

As a cytochemical control, fixed and unfixed cells were either treated with Po and DAB or with DAB only. Specificity of Con $A$ binding was checked by immersing the fixed and unfixed cells in PBS containing $0.25 \mathrm{M} \alpha$-methyl-D-mannoside followed by Con A treatment in the presence of a similar concentration of the sugar. In addition, some Con A-Po-labeled living cells were incubated for up to $3 \mathrm{hr}$ at $37^{\circ}$ in PBS containing metabolic inhibitors. Phagocytotic activity was studied by incubating the untreated cells in Po PBS-solution, $100 \mu \mathrm{g} / \mathrm{ml}$, at $37^{\circ}$.

\section{RESULTS}

\section{CON A BINDING SITES IN FIXED FIBROBLASTS}

Four to five cell lines of fibroblasts from CF homozygotes (CF), CF heterozygotes $(\mathrm{H})$, and normal individuals (Con) at exponential phase or plateau phase of growth were studied. The cell lines and subculture numbers and experimental conditions were listed in Table 1.

Reaction products, indicative of Con A binding sites or mannose-like sugar residues, were always seen as a continuous coat of $300-500 \AA$ thickness at the external surface of the plasma membrane (Figs. 1 and 2). Pinocytic vesicles were strongly stained (Fig. 1). Some multivesicular bodies showed positive reaction (Figs. 1 and 3 ). Concentrations of Con A from 4-800 $\mu \mathrm{g} / \mathrm{ml}$ were tested. Reactions were weak at $4 \mu \mathrm{g}$ Con $\mathrm{A}$, whereas Con A above $40 \mu \mathrm{g} / \mathrm{ml}$ gave consistent results. Therefore, $50 \mu \mathrm{g} / \mathrm{ml}$ was the standard concentration employed for this study. Omission of Con A resulted in the complete disappearance of staining. The cells subjected to DAB reaction showed a positive staining only in microbodies because of endogenous catalase activity. $\alpha$-Methyl-D-mannoside completely inhibited Con A binding (Fig. 4).

Although there was positive staining of some multivesicular bodies (Figs. 1 and 3), other organelles as well as the cytomembranes of smooth and rough endoplasmic reticulum, nuclear envelope, and Golgi apparatus were all unreactive. All experimental manipulations as those mentioned previously in "Materials and Methods" failed to alter the permeability of these cytomembranes which remained unstained. Even bisected fibroblasts at the cut surface of frozen sections failed to show any positive cytomembrane staining.

The distribution of reaction products within the fibroblasts of the three genotypes was carefully compared. No significant differences, however, were found among the three genotypes of both exponential and plateau growth phase cells. Measurements of reaction product thickness at the cell surface were attempted on vertically re-embedded monolayer cells, but no conclusions could be made because of considerable regional differences.

\section{CON A-INDUCED CELLULAR CHANGES IN LIVING FIBROBLASTS}

Since the Con A-Po technique did not show cytomembrane binding sites in fixed cells, living fibroblasts were used for the following experiments.

Effects of Temperature. Preliminary experiments showed that cellular changes occurred while the living cells were exposed to Con $A$ and subsequently to Po at either $37^{\circ}$ or room temperature. Many vesicles and vacuoles of positive $\mathrm{DAB}$ reaction were found in the cytoplasm at the completion of the Con A-Po labeling. In this condition, some plasma membranes have already been internalized during Con $A$ treatment and therefore escape Po coupling. Since Con A may stimulate phagocytosis (18), free Po could be phagocytosed during Po coupling; thus some Po-positive vesicles in the cytoplasm may represent nonspecific Po labeling. Therefore, DAB-positive membranes and organclles might not necessarily represent internalized plasma membrane when Con A-Po labeling was performed at elevated temperature.

The Con A treatment and Po coupling was carried out at $4^{\circ}$. Cells were washed at $4^{\circ}$ then incubated either at $37^{\circ}$ or $4^{\circ}$ in PBS for varying periods of time. The Con A-Po-labeled living cells without subsequent warm incubation consistently revealed a stretched, slender cell shape and the external side of the plasma membrane was continuously DAB positive for up to $3 \mathrm{hr}$ of cold incubation. Pinocytic vesicles were also positive, but there was no cytoplasmic staining. The cold Con A-Po procedure enabled all portions of plasma membranes to be labeled without changing the cell shape. Therefore, we employed cold labeling technique as our standard procedure.

Membrane Internalization and Cap Formation. The Con Atreated cells incubated at $37^{\circ}$ revealed conspicuous morphologic alterations accompanied by redistribution of binding sites. The cells would round up with most slender microvilli and pinocytic vesicles disappearing. Cytoplasmic vesicles and vacuoles of various sizes and shapes labeled with positive DAB reaction products were also present (Figs. 5-7). This clearly indicated that these positive vesicles and vacuoles were internalized plasma membrane. The vesicles and vacuoles tended to form clusters (Fig. 5) close to the Golgi apparatus (Fig. 6). In cells with longer incubation (60 min or more), foci of conspicuous indentation and protrusion of positively stained plasma membranes were observed (Fig. 7). These foci appeared to be cap formations caused by lateral movement of the receptor sites. The caps became larger with longer incubation. The staining of other portions of

Table 1. Concanavalin $A$ binding sites in fixed fibroblasts of three genotypes in vitro ${ }^{1}$

\begin{tabular}{|c|c|c|c|c|c|c|}
\hline Experimental conditions & Exp & nential & hase & & Plateau $\mathrm{p}$ & ohase \\
\hline Standard Con A-Po procedure & $\begin{array}{l}\mathrm{CF} 29_{15}{ }^{2} \\
\mathrm{CF} 24_{5} \\
\mathrm{CF} 35_{5} \\
\mathrm{CF} 24_{9} \\
\mathrm{CF} 34_{9}\end{array}$ & $\begin{array}{l}\mathrm{H} 25_{15} \\
\mathrm{H} 22_{\mathrm{s}} \\
\mathrm{H} 29_{\mathrm{s}} \\
\mathrm{H} 19_{9} \\
\mathrm{H} 30_{\mathrm{g}}\end{array}$ & $\begin{array}{l}\operatorname{Con} \mathrm{U}_{15} \\
\operatorname{Con} \mathrm{X}_{5} \\
\operatorname{Con} \mathrm{Z}_{5} \\
\operatorname{Con} \mathrm{X}_{9} \\
\operatorname{Con} \mathrm{Y}_{10}\end{array}$ & $\begin{array}{l}\mathrm{CF}_{17} \\
\mathrm{CF} 24_{9} \\
\mathrm{CF}_{4}\end{array}$ & $\begin{array}{l}\mathrm{H} 14_{15} \\
\mathrm{H} 19_{9} \\
\mathrm{H} 30_{9}\end{array}$ & $\begin{array}{l}\text { Con } T_{18} \\
\operatorname{Con} X_{9} \\
\operatorname{Con} Y_{10}\end{array}$ \\
\hline
\end{tabular}

Long Con A-Po procedure

Freezing and thawing, long Con A-Po

Long fixation: $3 \%$ GLA plus $1 \%$ PFA

Total no. of cell lines used and no. of repetitions
CF, 4 lines; 5 times
H, 5 lines
Con, 4 lines; 5 times

$$
\begin{array}{lll}
\mathrm{CF}_{17} & \mathrm{H} 14_{15} & \text { Con } \mathrm{T}_{1 \mathrm{~s}} \\
\mathrm{CF}_{17} & \mathrm{H} 14_{15} & \text { Con } \mathrm{T}_{18} \\
\mathrm{CF} 21_{22} & \mathrm{H} 26_{21} & \text { Con } \mathrm{R}_{18}
\end{array}
$$

CF, 4 lines; 6 times

$\mathrm{H}, 4$ lines; 6 times

Con, 4 lines; 6 times

${ }^{1}$ Con A: concanavalin A; Po: horseradish peroxidase; CF: cystic fibrosis line; H: heterozygous line; Con: control line; GLA: glutaraldehyde; PFA: paraformaldehyde.

${ }^{2}$ Numerals as subscripts refer to the subculture number. 

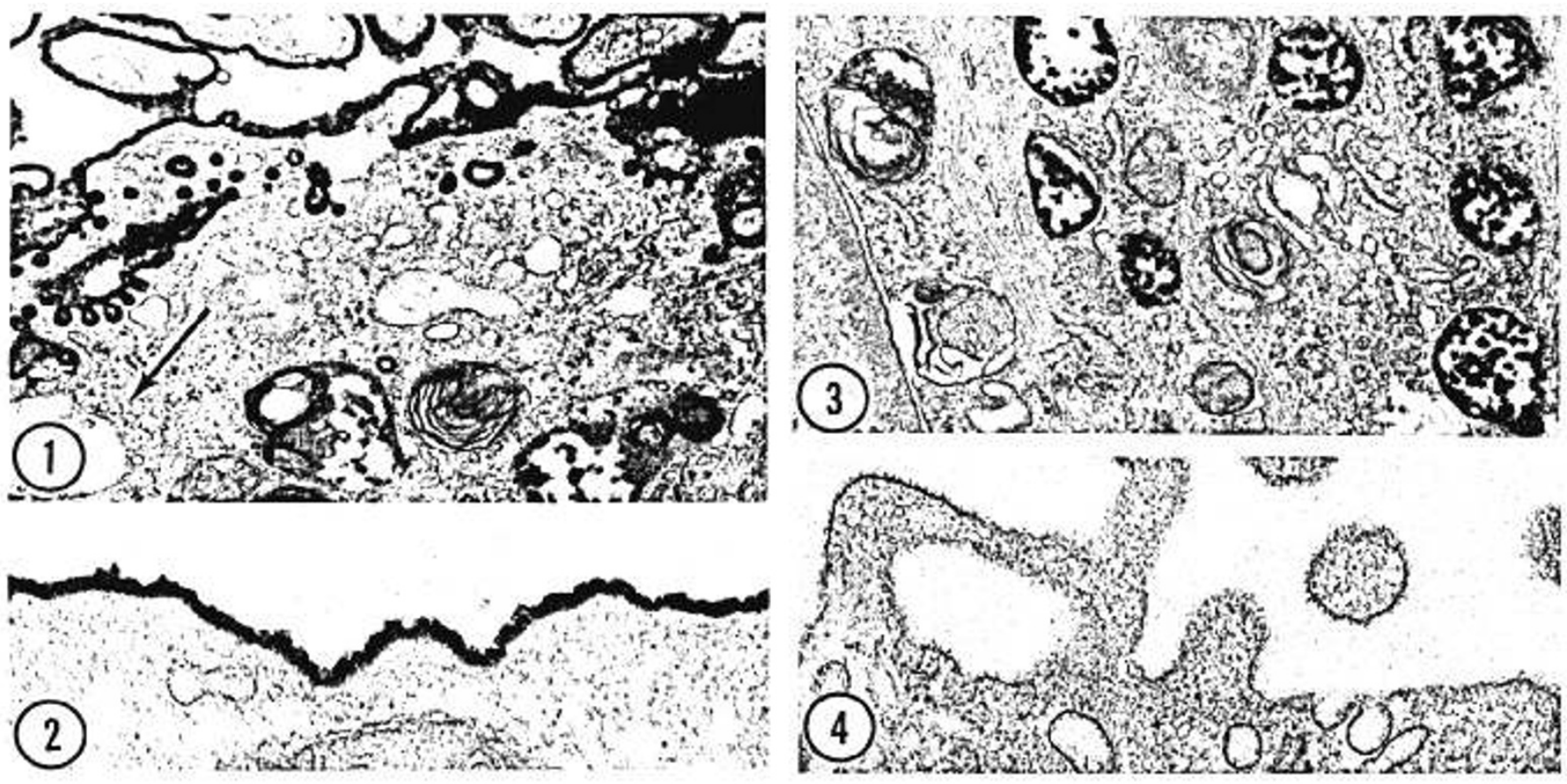

Figures 1-4 were prefixed fibroblasts.

Fig. 1. Cultured fibroblast of cell line $\mathrm{H} 14$ (heterozygote) in plateau growth phase are fixed and stained by concanavalin A-horseradish peroxidase. The staining is on the cell surface and within pinocytic vesicles as well as in multivesicular bodies. Note a multivesicular body without staining (arrow). Endoplasmic reticulum, nuclear envelope, and Golgi apparatus are free of reaction product (not shown in this portion of the figure). Magnification, $\times 25,000$

Fig. 2. Fixed fibroblasts of cell line Con $\mathrm{T}$ (normal individual) in plateau growth phase are stained by concanavalin A-horseradish peroxidase, showing a continuous staining on the cell surface. Other staining properties are identical with Figure 1. Magnification, $\times 60,000$.

Fig. 3. Fixed fibroblasts of cell line Con $\mathrm{T}$ are stained by concanavalin A-horseradish peroxidase. Positive staining is found in several multivesicular bodies. However, mitochondria, Golgi apparatus, nuclear envelope, and lysosomes are negative. Magnification, $\times 25,000$.

Fig. 4. The fibroblasts of Con $\mathrm{R}$ line in plateau phase are fixed and exposed to $0.25 \mathrm{M} \alpha$-methyl-D-mannoside then reacted with concanavalin $\mathrm{A}$ in the presence of the same molar concentration of mannoside. This procedure completely inhibits the staining and showed sugar specificity of the concanavalin A binding. Magnification, $\times 60,000$.

cell surface occasionally became spotty or patchy (Fig. 5), although staining persisted and was continuous in most of the cells, even after $3 \mathrm{hr}$ of incubation (Fig. 7). In these cells, internalized membrane and invaginated parts of the plasma membrane showed a stronger reaction, indicating that Con $\mathrm{A}$ binding sites were moved laterally and vertically. A strong reaction was noticed on the cell surface where cells were in contact. Omission of Con $A$ treatment and addition of $\alpha$-methyl-D-mannoside resulted in the complete loss of both staining and cellular changes. The cellular response was abolished when the living cells were Con A-Po treated and incubated in warm PBS containing either $50 \mathrm{mM}$ sodium azide or $10 \mathrm{mM}$ dinitrophenol. Plasma membrane staining, however, persisted. The phagocytosis of Po by untreated fibroblasts was negligible because the cells seldom showed any positive phagosomes after $3 \mathrm{hr}$ of incubation in warm Po solution.

Comparison of Three Genotype Fibroblasts. Six different fibroblast lines from $\mathrm{CF}$, four lines from heterozygotes, and five lines from normal individuals were repeatedly studied in both exponential and plateau phase of cell growth. Cellular responses to Con $\mathrm{A}$ such as cap formation, membrane internalization, and persistence of stronger staining at the region of cell contact were essentially the same among the three genotype fibroblasts.

\section{DISCUSSION}

The present study has demonstrated positive Con A binding sites (receptors) on the cell surface of cultured human fibroblasts from CF patients, CF heterozygotes, and normal individuals by the Con A-Po technique originally developed by Bernard and Avrameas (7). Since Con A binds specifically with $\alpha$-D-mannopyranose or $\alpha$-D-glucopyranose sugar residues (20), it has been used as a molecular probe for the surface sugar residues. The positive staining at the cell surface and inhibition by $\alpha$-methyl-Dmannoside clearly indicates the presence of mannose-like sugar residues on the cell surface of human cultured fibroblasts. The Con A binding sites were also detected by ferritin labeling technique (37). The results are in agreement with those of previous investigators using the Po and ferritin labeling technique on various other types of cultured cells $(7,17,24,28)$.

Why most cytomembranes stained negatively is not clear. The Con A-Po technique showed some positive multivesicular bodies in fixed cells. Thus, inability of Con A to penetrate cytomembrane can be ruled out. Attempts to increase the permeability of Con A by freezing and thawing, dimethylsulfoxide washing as well as prolonged Con $A$ exposure failed to achieve positive staining. Moreover, the in vivo fibroblasts in scar tissue did not show cytomembrane staining, although positive Con A-Po staining in cytomembrane of rat cerebellar Purkinje cells (36) and in tubular epithelial cells of mouse kidney (38) has been reported. Lack of staining does not necessarily indicate the complete absence of binding sites at the cytomembranes. The binding sites may be present but are somehow masked. This assumption seems plausible. First, the presence of Con A binding sites at the cisternal side of the granular endoplasmic reticulum membrane was demonstrated by Hirano et al. (23) with the ferritin labeling technique in homogenates of cultured myeloma cells. Second, positive and negative cytomembranes were always intermingled in both Purkinje cells (36) and renal tubule cells (38), indicating either masking or regional differences of surface sugar residues.

The time course of Con A-induced cellular changes was characterized by the successful Con $A$ and Po labeling of cell surface at low temperature. Cold Con A-Po labeling showed continuous positive staining at whole cell surface without membrane movement. Therefore, cold Con A-Po labeling with subsequent warm incubation made it possible to trace the movement of plasma 

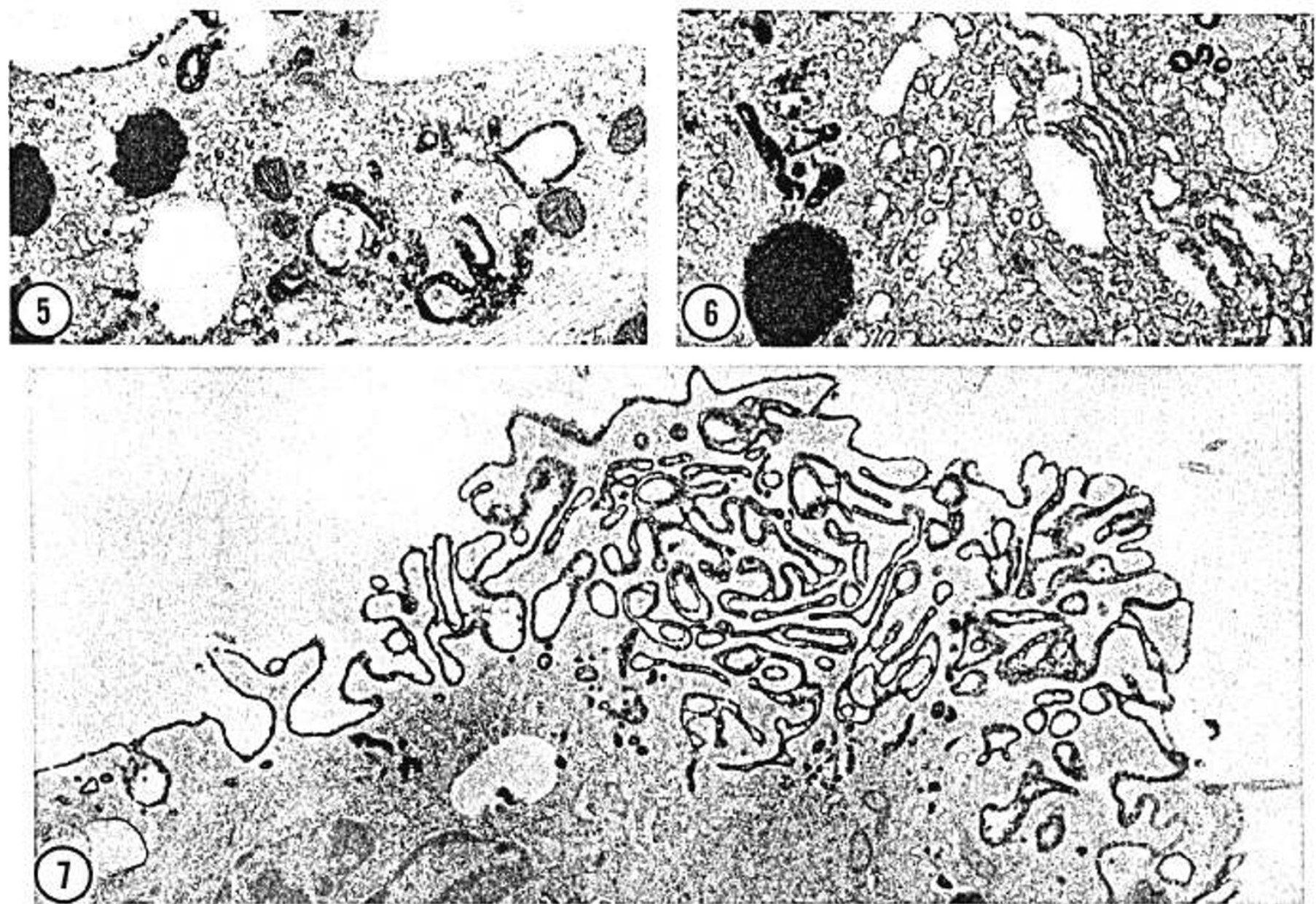

Figures 5-7 show unfixed fibroblasts which are concanavalin A-horseradish peroxidase labeled at low temperature followed by another incubation.

Fig. 5. A fibroblast of CF34 line in plateau growth phase is concanavalin A-horseradish peroxidase-labeled in cold but incubated at $37^{\circ}$. The clusters of positively stained vesicles of various sizes and shapes in the cytoplasm indicate the internalized plasma membrane. Note that internalized membrane has stronger staining than the cell surface which may show scanty or patchy staining. Magnification, $\times 25,000$.

Fig. 6. A cell of CF20 line in exponential growth phase contains concanavalin A-horseradish peroxidase (Con A-Po)-positive vesicles in the vicinity of a Golgi apparatus. The cells are Con A-Po labeled in cold and incubated at $37^{\circ}$ for $2 \mathrm{hr}$. Magnification, $\times 42,000$.

Fig. 7. A cell of Con BB line in exponential growth phase shows a marked indentation of plasma membrane at one pole of the cell (cap formation). These indented membranes are concanavalin A-horseradish peroxidase positive. Note the internalized vesicles and persistence of continuous surface staining. Cold Con A-Po labeling and $2 \mathrm{hr}$ of warm incubation. Magnification $\times 18,000$.

membrane. The fibroblasts labeled by Con A-Po at low temperature showed marked "cap" formation and membrane internalization after warm incubation. Ultrastructurally, cap formation was demonstrated by the presence of an area of infoldings, protrusions, and invaginations of the plasma membrane. The plasma membrane of this region was strongly stained by Con APo and corresponded to the foci of cap formation seen in light microscopy. The rest of the cell surface stained weakly and sometimes spottily. These changes occur as a result of lateral movement and aggregation of binding sites induced by Con $\mathrm{A}$ as proposed in the fluid mosaic model of biologic membranes (34). Results of the present study showed definitely that the nontransformed fibroblasts produced caps after Con A treatment, in contrast to negative data reported by others (31). The mobility of binding sites, however, was significantly slower in normal human fibroblasts that in SV40-transformed CF cells (37), as has been demonstrated on various transformed cells $(6,24,28,31$, 32).

After warm incubation, the Con A-Po-labeled fibroblasts showed a cluster of vesicles and vacuoles of various sizes and shapes in the cytoplasm. Since these vesicles and vacuoles were heavily stained, it is reasonable to assume that they represented plasma membrane internalized by the action of Con A. Phagocy- tosis of free Po can be excluded because free Po was thoroughly washed out after coupling, and the incubation medium did not contain Po. Furthermore, incubation of untreated fibroblasts in warm Po solution resulted in very few positive phagosomes in the cytoplasm. The internalization indicates vertical movements of the membrane components according to the concepts of current membrane models (34). Plasma membranes are known to be internalized by various kinds of ligands $(1,10,29)$ and were found in Golgi regions in some types of cells, suggesting membrane recycling (21).

Fixed fibroblasts of the three genotypes showed the same distribution of Con A binding sites. Live cells responded similarly to Con A treatment. The lack of demonstrable differences of receptor mobility in the membrane of the three fibroblast genotypes could not be attributed to technical limitations because increased membrane fluidity has been demonstrated in various transformed cells by this technique $(24,28,32)$. Rather, it is more likely that the three fibroblast genotypes have the same distribution of binding sites and the same receptor mobility as far as Con $\mathrm{A}$ is concerned. The absence of detectable differences in mannose-like sugar residues on the cell surface among the three fibroblast genotypes appears to be in agreement with previous reports which indicated an unaltered membrane transport of 
glucose, amino acid $(5,19)$, normal membrane enzymes (30), and protein composition of the plasma membrane $(2,16)$ in $C F$ cells.

\section{CONCLUSION}

Mannose-like sugar residues in the carbohydrate moieties of the fibroblast cell surface were visualized cytochemically using Con $A$ as a molecular probe and Po as a marker. In the fixed cells, the staining indicative of Con A binding sites was localized continuously on the external side of the plasma membrane. No difference was found among the three genotypes of cultured fibroblasts from CF patients, CF heterozygotes, and normal individuals. In living fibroblasts, Con $\mathrm{A}$ induced cap formation and internalization of plasma membrane. The movement of plasma membrane was successfully traced by Con A-Po labeling technique. There was no detectable difference in the mobility of Con $\mathrm{A}$ binding sites among three fibroblast genotypes.

\section{REFERENCES AND NOTES}

1. Antoine, J. C., Avrameas, S., Gonatas, N. K., Stieber, A., and Gontas, J. O.: Plasma membrane and internalized immunoglobulins of lymphnode cells studied with conjugates of antibody or its Fab fragments with horseradish peroxidase. J. Cell Biol., 63: 12 (1974).

2. Baig, M. M., Cetorelli, J. J., and Roberts, R. M.: Plasma membrane components of skin fibroblasts from normal individuals and patient with cystic fibrosis. J. Pediat., 86: 72 (1975).

3. Barranco, S. C., Bolton, W. E., Haenelt, B. R., and Abell, C. W.: Differences in the incorporation of thymidine into DNA of normal and cystic fibrosis fibroblasts in vitro. J. Cell. Physiol., 88: 33 (1976).

4. Bauer, P. S., Bolton, W. E., and Barranco, S. C.: Electron microscopy in microchemical analysis of cystic fibrosis diploid fibroblasts in vitro. Tex. Rep. Biol. Med., 34: 113 (1976).

5. Benke, P. J., Erbstoeszer, M., and Pitot, H. C.: Transport of labelled compounds in control and cystic fibrosis cells in vitro. Lancet, $i: 182$ (1972).

6. Berlin, R. D., Oliver, J. M., Ukena, T. E., and Yin, H. H.: The cell surface. New Engl. J. Med., 292: 515 (1975).

7. Bernard, W., and Avrameas, S.: Ultrastructural visualization of cellular carbohydrate components by means of concanavalin A. Exp. Cell Res., 64: 232 (1971).

8. Besley, G. T. N., Patrick, A. D., and Norman, A. P.: Inhibition of the motility of gill cilia of Dreissensia by plasma of cystic fibrosis patients and their parents. J. Med. Genet., 6: 278 (1969).

9. Bolton, W. E., and Barranco, S. C.: Characterization of the cell kinetics and growth properties of cystic fibrosis diploid fibroblasts in vitro. Amer. J. Human Genet., 27: 394 (1975).

10. Borat, N., and Avrameas, S.: Surface and intracellular localization of concanavalin $A$ in human lymphocytes. Exp. Cell Res., 76: 451 (1973).

11. Bowman, B. H., Barnett, D. R., Matalon, R., Danes, B. S., and Bearn, A. G.: Cystic fibrosis: Fractionation of fibroblast media demonstrating ciliary inhibition. Proc. Natl. Acad. Sci. U. S. A., 70: 548 (1973).

12. Bowman, B. H., Lankford, B. J., Fuller, G. M., Carson, S. D., Kurosky, A., and Barnett, D. R.: Cystic fibrosis: The ciliary inhibitor is a small polypeptide associated with immunoglobulin G. Biochem. Biophys. Res. Commun., 64: 1310 (1975).

13. Bowman, B. H., Lockhart, L. H., and McCombs, M. L.: Oyster ciliary inhibition by cystic fibrosis factor. Science, 164: 325 (1969).

14. Bowman, B. H., and Mangos, J.: Cystic fibrosis: Current concepts. New Engl. J. Med., 294: 937 (1976).

15. Chang, J. P.: A new technique for separation of coverglass substrate from epoxy-embedded specimens for electron microscopy. J. Ultrastruct. Res., 37: 370 (1971).

16. Changus, J. E., Quissell, D. O., Sukup, M. R., and Pitot, H. C.: Studies on the synthesis of plasma membrane proteins of fibroblasts from patient with cystic fibrosis. Amer. J. Pathol., 80: 317 (1975).

17. Collard, J. G., and Temmink, H. M.: Binding and cytochemical detection of cell bound concanavalin A. Exp. Cell Res., 86: 81 (1974).
18. Edelson, P. J., and Cohen, Z. A.: Effects of concanavalin A on mouse peritoneal macrophages. I. Stimulation of endocytic activity and inhibition of phago-lysosome formation. J. Exp. Med., 140: 1364 (1974).

19. Fletcher, D. S., and Lin, T.-Y.: Incorporation of L-leucine and D-glucosamine into skin fibroblasts derived from cystic fibrosis and normal individuals. Clin Chim. Acta, 44: 5 (1973).

20. Goldstein, I. J., Hollerman, C. E., and Smith, E. E.: Protein-carbohydrate interaction. II. Inhibition studies on the interaction of concanavalin A with polysaccharides. Biochemistry, 4: 876 (1965).

21. Gonatas, N. K., Steiber, A., Kim, S. U., Graham, D. I., and Avrameas, S.: Internalization of neuronal plasma membrane ricin receptors into the Golgi apparatus. Exp. Cell Res., 94: 426 (1975).

22. Graham, R. C., and Karnovsky, M. J.: The early stages of absorption of injected horseradish peroxidase in the proximal tubules of the mouse kidney: Ultrastructural cytochemistry by a new technique. J. Histochem. Cytochem., 14: 291 (1966).

23. Hirano, H., Parkhouse, B., Nicolson, G. L., Lennox, E. S., and Singer, S. J.: Distribution of saccharide residues on membrane fragments from a myeloma-cell hemogenate: Its implications for membrane biogenesis. Proc. Natl. Acad. Sci. U. S. A. 69: 2945 (1972).

24. Huet, C., and Bernard, W.: Differences in the surface mobility between normal and SV40- polyoma- and adenovirus transformed hamster cells. Int. J. Cancer, 13: 227 (1974).

25. Mangos, J. A., and McSherry, N. R.: Sodium transport: Inhibitory factor in sweat of patients with cystic fibrosis. Science, 158: 135 (1967).

26. Mangos, J. A., and McSherry, N. R.: Studies on the mechanism of inhibition of sodium transport in cystic fibrosis of the pancreas. Pediat. Res., 2: 378 (1968).

27. Matalon, R., and Dorfman, A.: Acid mucopolysaccharides in cultured fibroblasts of cystic fibrosis of the pancreas. Biochem. Biophys. Res. Commun., 33: 954 (1968).

28. Nicolson, G. L.: Interactions of lectins with animal cell surfaces. Int. Rev. Cytol., 39: 89 (1974).

29. Nicolson, G. L., Lacorbiere, M., and Hunter, T. R.: Mechanism of cell entry and toxicity of an affinity-purified lectin from Ricinus communis and its differential effects on normal and virus-transformed fibroblast. Cancer Res., 35: 144 (1975).

30. Quissell, D. O., and Pitot, H. C.: Number of oubain binding sites in fibroblasts from normal subjects and patients with cystic fibrosis. Nature, 247: 115 (1974).

31. Rosenblith, J. Z., Ukena, T. E., Yin, H. H., Berlin, R. D., and Karnovsky, M. J.: A comparative evaluation of the distribution of concanavalin A binding sites on the surfaces of normal virally-transformed and protease treated fibroblast. Proc. Natl. Acad. Sci. U. S. A. 70: 1625 (1973).

32. Rowlatt, C., Wicker, R., and Bernhard, W.: Ultrastructural distribution of concanavalin $\mathrm{A}$ receptors on hamster embryo and adenovirus tumor cell cultures. Int. J. Cancer, 11: 314 (1973).

33. Schmoyer, 1. R., and Baglia, F. A.: Cystic fibrosis: Effects of media from cultured cystic fibrosis fibroblasts on ATPase activity. Biochem. Biophys. Res. Commun., 58: 1066 (1974).

34. Singer, S. J., and Nicolson, G. L.: The fluid mosaic model of the structure of cell membranes. Science, 175: 720 (1972).

35. Spurr, A. R.: A low-viscosity epoxy resin embedding medium for electron microscopy. J. Ultrastruct. Res., 26: 31 (1969).

36. Wood, J. G., McLaughlin, B. J., and Barber, R. P.: The visualization of concanavalin A binding sites in Purkinje cell somata and dendrites of rat cerebellum. J. Cell Biol., 63: 541 (1974).

37. Yokoyama, M.: Unpublished data.

38. Yokoyama, M., Nishiyama, F., Irimura, T., and Hirano, H.: Lectin binding sites in mouse kidney tubule cells by peroxidase-labeling method. Proceedings of the Tenth Congress of Anatomy, Tokyo, p. 501 (Science Council of Japan, Tokyo, 1975).

39. The authors are grateful to Miss Debra M. Hodges for her technical assistance and to Mrs. Margaret Rowden for her secretarial assistance.

40. This research was supported by Program Project AM 17040 from National Institutes of Health, United States Public Health Service.

41. Requests for reprints should be addressed to: J. P. Chang, Ph.D., Division of Cell Biology, Department of Human Biological Chemistry and Genetics, University of Texas Medical Branch Galveston, Tex. 77550 (USA).

42. Received for publication July 13,1976 .

43. Accepted for publication November 18, 1976. 